OPEN ACCESS

Edited by:

Silvia Buroni,

University of Pavia, Italy

Reviewed by:

Walter Zingg,

Geneva University Hospitals (HUG),

Switzerland

Ewa Szczuka,

Adam Mickiewicz University

in Poznañ, Poland

Marine Butin,

Hocpices Civils de Lyon, France

*Correspondence:

Yue Qu

yue.qu@monash.edu

Anton Y. Peleg

anton.peleg@monash.edu

Trevor Lithgow

trevor.lithgow@monash.edu

Specialty section:

This article was submitted to Antimicrobials, Resistance

and Chemotherapy,

a section of the journal

Frontiers in Microbiology

Received: 10 December 2019

Accepted: 17 April 2020

Published: 13 May 2020

Citation:

QU Y, Li Y, Cameron DR,

Easton CD, Zhu X, Zhu M,

Salwiczek M, Muir BW, Thissen $H$,

Daley A, Forsythe JS, Peleg AY and Lithgow T (2020) Hyperosmotic

Infusion and Oxidized Surfaces Are

Essential for Biofilm Formation

of Staphylococcus capitis From

the Neonatal Intensive Care Unit.

Front. Microbiol. 11:920.

doi: 10.3389/fmicb.2020.00920

\section{Hyperosmotic Infusion and Oxidized Surfaces Are Essential for Biofilm Formation of Staphylococcus capitis From the Neonatal Intensive Care Unit}

Yue Qu ${ }^{1,2,3 *}$, Yali Li i,5, David R. Cameron'2, Christopher D. Easton ${ }^{4}$, Xuebo Zhu', Minli Zhu', Mario Salwiczek ${ }^{2,4}$, Benjamin W. Muir ${ }^{4}$, Helmut Thissen ${ }^{4}$, Andrew Daley ${ }^{6,7}$, John S. Forsythe ${ }^{5}$, Anton Y. Peleg ${ }^{2,3 *}$ and Trevor Lithgow ${ }^{2 *}$

\begin{abstract}
${ }^{1}$ The Neonatal Intensive Care Unit, The Second Affiliated Hospital and Yuying Children's Hospital of Wenzhou Medical University, Wenzhou, China, ${ }^{2}$ Infection and Immunity Theme, Department of Microbiology, Biomedicine Discovery Institute, Monash University, Clayton, VIC, Australia, ${ }^{3}$ Department of Infectious Diseases, The Alfred Hospital and Central Clinical School, Monash University, Melbourne, VIC, Australia, ${ }^{4}$ The Commonwealth Scientific and Industrial Research Organisation (CSIRO) Manufacturing, Clayton, VIC, Australia, ${ }^{5}$ Department of Materials Science and Engineering, Monash Institute of Medical Engineering, Monash University, Clayton, VIC, Australia, ${ }^{6}$ Department of Microbiology, The Royal Children's Hospital, Parkville, VIC, Australia, ${ }^{7}$ Department of Paediatrics, University of Melbourne, Parkville, VIC, Australia
\end{abstract}

Staphylococcus capitis is an opportunistic pathogen often implicated in bloodstream infections in the neonatal intensive care unit (NICU). This is assisted by its ability to form biofilms on indwelling central venous catheters (CVC), which are highly resistant to antibiotics and the immune system. We sought to understand the fundamentals of biofilm formation by S. capitis in the NICU, using seventeen clinical isolates including the endemic NRCS-A clone and assessing nine commercial and two modified polystyrene surfaces. S. capitis clinical isolates from the NICU initiated biofilm formation only in response to hyperosmotic conditions, followed by a developmental progression driven by ica $A D B C$ expression to establish mature biofilms, with polysaccharide being their major extracellular polymer substance (EPS) matrix component. Physicochemical features of the biomaterial surface, and in particular the level of the element oxygen present on the surface, significantly influenced biofilm development of $S$. capitis. A lack of highly oxidized carbon species on the surface prevented the immobilization of S. capitis EPS and the formation of mature biofilms. This information provides guidance in regard to the preparation of hyperosmolar total parenteral nutrition and the engineering of CVC surfaces that can minimize the risk of catheter-related bloodstream infections caused by S. capitis in the NICU.

Keywords: Staphylococcus capitis, biofilms, bloodstream infections, NICU, central venous catheters, surface chemistry, oxidized surfaces

\section{INTRODUCTION}

Premature newborns given intensive care and prolonged hospitalization in the neonatal intensive care unit (NICU) are peculiarly prone to infections, due to their immature immune system and invasive medical procedures such as catheterization (Beck-Sague et al., 1994). Catheter-related bloodstream infections (CRBSI) are common and occur at a rate of 1-18 infections per 1,000 central 
line days (Blanchard et al., 2013; Yumani et al., 2013; DubbinkVerheij et al., 2017). These infections are often associated with significant mortality and morbidity and contribute to high healthcare costs (Payne et al., 2004).

Staphylococcus capitis is an emerging opportunistic pathogen causing bloodstream infections in the NICU (Wang et al., 1999; Rasigade et al., 2012; Cui et al., 2013; Cheong et al., 2016). Neonatal patients infected with $S$. capitis often experience more severe morbidity relative to that of non-S. capitis coagulasenegative staphylococci (CoNS) (Ben Said et al., 2016). One specific clone of $S$. capitis, NRCS-A, was found to be highly endemic in the NICU and may have caused most $S$. capitis sepsis in neonatal patients worldwide (Butin et al., 2017a,b; Stenmark et al., 2019). In the NICU, S. capitis has been frequently isolated from central venous catheters (CVCs) explanted from CRBSI patients, supporting an important role of CVCs as the reservoir of invading bacteria (Ory et al., 2019). Past studies suggested that biofilm formation by $S$. capitis on medical devices such as CVCs correlates with its potential to establish infections (De Silva et al., 2002; Bradford et al., 2006). A direct link between neonatal sepsis caused by $S$. capitis and CVC implantation, however, has been questioned (Wang et al., 1999; Butin et al., 2019). Regardless, the importance of medical device surfaces as a host for bacterial colonization and biofilm formation has been well-established (Salwiczek et al., 2014). Direct contamination of implanted CVCs by bacteria from the NICU environment, patients' skin or microbial translocation from the gut, throat or nostrils of patients, and subsequently bacterial adherence and biofilm formation are considered the key initiating steps of CRBSI (Hitzenbichler et al., 2017).

Antibiotic treatments of S. capitis infections in the NICU are often suboptimal due to their intrinsic and emerging resistance to many first-line antibiotics, and their capacity to form biofilms on implanted medical devices (Butin et al., 2015, 2019; Zhou et al., 2015). Biofilm formation is a self-defensive strategy of many microorganisms to survive adverse environments including long-term antibiotic exposure (Otto, 2008, 2013). For members of the genus Staphylococcus, including Staphylococcus aureus, Staphylococcus epidermidis and S. capitis, a characteristic feature of their biofilm formation is the inter-cellular adhesion associated with the production of polysaccharide intercellular adhesin (PIA), a linear $\beta$-glucosaminoglycan (Poly- $\beta$-1,6GlcNAc) attached to the cell surface (Mack et al., 1994; Heilmann et al., 1996; Cui et al., 2013). The synthesis and secretion of PIA in staphylococci depends on the gene cluster icaADBC; disruption of $i c a A D B C$ prevents cellular aggregation and biofilm formation (Gerke et al., 1998; Vermont et al., 1998; Frebourg et al., 2000; Galdbart et al., 2000; Arciola et al., 2001; Cui et al., 2013).

New antibiofilm strategies such as ethanol lock therapy and impregnating catheter surfaces with antibiotics have been recently examined in large-scale clinical trials targeting pediatric and neonatal patients (Wolf et al., 2018; Gilbert et al., 2019). Failure of these strategies in preventing CRBSI in young populations highlights an urgent need for more effective prophylaxis. This study sought to establish a comprehensive understanding of the interactions between $S$. capitis and biomaterials at the pathogen-medical device interface, and to provide valuable insights into more effective preventative strategies against CRBSI caused by $S$. capitis in the NICU.

\section{MATERIALS AND METHODS}

\section{Strains and Growth Conditions}

Seventeen $S$. capitis clinical isolates (isolates $6,8,11,17,18,19$, $21,25,44,52,57,61,70,76,77,80,91)$ from blood cultures of infants at the Royal Women's Hospital NICU (Parkville, Victoria, Australia) with confirmed bloodstream infections were used in this study for biofilm formation under different conditions. All isolates except isolates 44 and 77 belong to S. capitis subsp. urealyticus; isolates 44 and 77 belong to S. capitis subsp. capitis (Cui et al., 2013). These isolates typify a large collection of strains responsible for 55 episodes of sepsis in the NICU over the period 2000-2005 (Bradford et al., 2006; Cui et al., 2013). Eight isolates belonging to the unique NRCS-A clone (isolates $6,8,11,17,18,19,21$, and 25), based on smal pulsed-field gel electrophoresis (PFGE) analysis were further selected to study interactions between $S$. capitis and biomaterials with different surface characteristics (D'mello et al., 2008; Butin et al., 2017b). Biofilm-positive S. epidermidis strain RP62A (ATCC 35984) and biofilm-negative S. hominis strain SP2 (ATCC 35982) were included as controls for biofilm production.

\section{Biofilm Cultivation and Imaging}

Bacterial biofilms were cultured in 96-well microplates and quantitatively assessed using an established method (Deighton et al., 2001). Tryptic soya broth (TSB, Oxoid), TSB with $4 \% \mathrm{NaCl}$, TSB with $1 \%$ glucose, and TSB with $4 \%$ ethanol were selected as biofilm growth media representing different environmental cues encountered in the NICU. Nine commercially available polystyrene microplates with different surface characteristics were tested, including DNA-BIND (Corning), Carbo-BIND (Corning), Universal-BIND (Corning), Not Treated (Corning), CellBIND (Corning), Ultra-Low-Attachment (Corning), Immobilizer (Corning), Tissue Culture Polystyrene (TCPS) from NUNC, and TCPS from BD Falcon. Biofilms were also established on 96-well microplate cutouts (BD Falcon) using TSB with $4 \% \mathrm{NaCl}$ and qualitatively examined with confocal laser scanning microscopy (CLSI) as described previously (Qu et al., 2009). CLSI images were obtained on a Leica SP5 microscope. SYTO-9 (3.35 $\left.\mu \mathrm{M}, 15 \mathrm{~min}, 22^{\circ} \mathrm{C}\right)$ and Alexa Fluor 555 conjugated wheat germ agglutinin (WGA, $10 \mu \mathrm{g} / \mathrm{mL}, 1 \mathrm{~h}$, $22^{\circ} \mathrm{C}$ ) were used to stain the biofilms sequentially. All biofilm experiments for quantitative analysis were repeated at least three times in triplicate, and qualitative assays were repeated at least three times.

\section{Structural Analysis of S. capitis Biofilms}

The composition of $S$. capitis biofilms was analyzed by treating mature biofilms with extracellular polymer substance (EPS) matrix-disrupting chemicals/enzymes respectively, including DNase $\mathrm{I}$ at $5 \mathrm{mg} / \mathrm{mL}$, proteinase $\mathrm{K}$ at $100 \mu \mathrm{g} / \mathrm{mL}$, and sodium metaperiodate $\left(\mathrm{NaIO}_{4}\right)$ at $10 \mathrm{mM}$, for $2 \mathrm{~h}$ at $37^{\circ} \mathrm{C}$ with shaking (75 rpm) (Qin et al., 2007). Different buffers were used to prepare 
chemical/enzymatic solutions $\left(5 \mathrm{mM} \mathrm{MgCl}_{2}\right.$ and $5 \mathrm{mM} \mathrm{CaCl}_{2}$ for DNase I, $20 \mathrm{mM}$ Tris- $\mathrm{HCl}$ and $5 \mathrm{mM} \mathrm{CaCl}$ for proteinase $\mathrm{K}$, and $50 \mathrm{mM}$ sodium acetate, $\mathrm{pH}=4.5$ for $\mathrm{NaIO}_{4}$ ). This was to ensure the maximum efficacy and stability of these reagents. Control wells were treated with buffer alone. The biofilm composition analysis assays were repeated at least three times in triplicate.

\section{qPCR Analysis}

Quantitative real-time (qRT)-PCR was used to assess expression of icaADBC and icaR by $S$. capitis after growth in TSB or TSB with $4 \% \mathrm{NaCl}$ at $37^{\circ} \mathrm{C}$ for $5.5 \mathrm{~h}$ (Chaffin et al., 2012). Primers were designed based upon the ica sequence of $S$. capitis isolate 6 (Genbank JF930147.1; Table 1). As an internal control, $16 \mathrm{~S}$ rRNA levels were quantified. Relative gene expression was determined using the $2^{-\Delta \Delta \mathrm{C}_{\mathrm{T}}}$ method (Schmittgen and Livak, 2008). These experiments were repeated on three different occasions in technical triplicate.

\section{Atomic Force Microscopy (AFM)}

An Asylum Research MFP-3D atomic force microscope (Santa Barbara, CA) was used to assess the surface topography of the bottom of microwells in different polystyrene microplates. Tapping mode was used for imaging in air with ultrasharp silicon nitride tips (NSC15 non-contact silicon cantilevers, Mikro-Masch, Spain). The tips had a typical force constant of $40 \mathrm{~N} / \mathrm{m}$ and a resonant frequency of $320 \mathrm{kHz}$. Typical scan settings involved the use of an applied piezo deflection voltage of $0.6-0.7 \mathrm{~V}$ at a scan rate of $0.8 \mathrm{~Hz}$. All images were processed (1st order flattening algorithm) using Igor Pro software and arithmetic mean roughness $(\mathrm{Ra})$ values were extracted. The experiments were repeated three times.

\section{X-Ray Photoelectron Spectroscopy (XPS) Analysis}

XPS analysis was performed on the bottom of microwells originating from 96-well microplates using an AXIS HSi spectrometer (Kratos Analytical Ltd., United Kingdom) equipped with a monochromated Al-K $\alpha$ X-ray source at a power of $144 \mathrm{~W}$

TABLE 1 | Oligonucleotide primers used in this study.

\begin{tabular}{ll}
\hline$i c a R F$ & CCATAGATATATTGGAGGGATCA \\
$i c a R R$ & GTCCAATATCCAGTGCACC \\
$i c a A F$ & TATGAACCACGTGCCATGTG \\
$i c a A R$ & CTCATGTCCACCTTAGCC \\
$i c a D F$ & AGGGAGAGCTTATCATTGCG \\
$i c a D R$ & CTCCACGTTAAGAGCGATACG \\
$i c a B F$ & GGATATGATCACGCAGCCTC \\
$i c a B R$ & GCAGACACATTAGACGCCTC \\
$i c a C F$ & CACGGTCAAATGATAAGCGC \\
$i c a C R$ & GAAACCGCTAAGAAGACGACC \\
$16 S$ rRNA $F^{\mathrm{a}}$ & AGCAACGCGAAGAACCTAC \\
$16 S$ rRNA $R^{\mathrm{b}}$ & CAACATCTCACGACACGAGC \\
\hline
\end{tabular}

${ }^{\mathrm{a}} \mathrm{F}$, forward. ${ }^{\mathrm{b}} \mathrm{R}$, reverse.
$(12 \mathrm{~mA}, 12 \mathrm{kV})$. Instrument settings can be found elsewhere (Li et al., 2014). XPS analysis was performed using a method similar to that previously reported (Telford et al., 2012). Data processing was performed using CasaXPS processing software version 2.3.15 (Casa Software Ltd., Teignmouth, United Kingdom). Binding energies were referenced to the $\mathrm{C} 1 \mathrm{~s}$ peak at $284.8 \mathrm{eV}$ (aromatic hydrocarbon). These experiments were repeated on three different occasions in duplicate.

\section{Surface Modification of Untreated Polystyrene Microplates}

Ozone treatment and diethylene glycol dimethyl ether plasma polymer (DGpp) deposition were carried out on untreated polystyrene surfaces (Corning Not Treated microplates) to provide an oxidized surface chemistry. For ozone treatment, the microplate was placed in a UV/Ozone ProCleaner ${ }^{\mathrm{TM}}$ (BioForce) and exposed for $5 \mathrm{~min}$. For DGpp deposition, plasma polymerization was carried out in a custom-built plasma reactor described previously (Li et al., 2014). The plasma deposition of films was performed using a frequency of $125 \mathrm{kHz}$, load power of $50 \mathrm{~W}$ and initial monomer pressure of $20 \mathrm{~Pa}$ with a treatment time of $120 \mathrm{~s}$ (final pressure $61 \mathrm{~Pa}$ ).

\section{Immobilization of Biofilm EPS Matrix on Microplate Surfaces}

EPS matrix was isolated from staphylococcal biofilms following the method described by Taff et al. (2012). Biofilm matrix supernatants $(100 \mu \mathrm{L})$ were added into microwells in TCPS microplates (BD Falcon) and Not Treated microplates (Corning) and incubated for 3 or $20 \mathrm{~h}$, at $37^{\circ} \mathrm{C}$ with gentle shaking (75 rpm). After washing with distilled water, the biofilm matrices immobilized on the surfaces were stained with Alexa Fluor 488 conjugated WGA $(10 \mu \mathrm{g} / \mathrm{mL}, 1 \mathrm{~h}$ in the dark) before imaging with an Olympus IX81 fluorescence microscope. Three biological repeats were carried out for this experiment.

\section{Biofilm Formation and Surface Chemistry of Pediatric Central Venous Catheters}

Pediatric double-lumen central venous catheters with blue FlexTip $^{\circledR}$ (CVCs, Arrow, Teleflex Medical, North Carolina, United States) were pre-treated with fetal bovine serum (SigmaAldrich, Sydney, Australia) overnight before biofilm growth or surface chemistry analysis. This was to mimic the pre-exposure of implanted CVCs to human serum in late-onset catheter related bloodstream infections. CVCs were washed twice with PBS and cut to sections of $5 \mathrm{~mm}$ for biofilm analysis or $15 \mathrm{~mm}$ for surface chemistry analysis. For qualitative biofilm analysis, catheter sections were cultivated with $S$. capitis isolate 6 in TSB with $4 \% \mathrm{NaCl}$ at $1 \times 10^{7} \mathrm{CFU} / \mathrm{mL}$ for $24 \mathrm{~h}$, cut open in the middle, and prepared for scanning electron microscopy (Uwamahoro et al., 2012). For catheter surface chemistry analysis, all samples were suspended over the sample bar using a mask. To analyze the interior surface of the catheter, the double-lumen tube was cut open in the middle, and carefully 
spread flat. XPS analysis and data analysis were performed as described before. Untreated CVCs were also tested to make comparisons. Surface chemistry analysis of the CVC was repeated three times in duplicate, and biofilm scanning eletron microscopy was repeated three times.

\section{Statistical Analyses}

To analyze differences in biofilm formation under different environmental conditions and on different surfaces, one-way ANOVA tests were performed with Minitab 19 for Windows using a significance level of 0.05 ( $p$-value). Spearman correlation test was performed to determine the strength of a monotonic relationship between biofilm formation of $S$. capitis and biomaterial surface properties.

\section{Ethics Review and Approval}

This study used strains obtained from RMIT University, Australia. Monash University did not require the study to be reviewed or approved by an ethics committee because these strains were provided to the research team in isolation from any references to individual patients. The Australian National Statement on Ethical Conduct in Human Research covers the use of human participants, their data, or tissues or body fluids. Using these microorganisms was not considered subject to ethical review by the Human Research Ethics Committee.

\section{RESULTS}

\section{Hyperosmotic Conditions Are Essential for S. capitis Biofilm Formation in the NICU}

BD falcon TCPS 96-well microplates were utilized for quantitative analysis of biofilm formation by $17 \mathrm{~S}$. capitis isolates under different environmental conditions. All these 17 S. capitis isolates carry ica locus (Cui et al., 2013). Twelve out of 15 S. capitis subp. urealyticus clinical isolates formed biofilms. Among them, 10 isolates only produced biofilms in response to hyperosmotic conditions $(4 \%(\mathrm{w} / \mathrm{v}) \mathrm{NaCl})$ but not under other environmental influences, such as TSB only, TSB with $1 \%$ glucose or $4 \%$ ethanol (Figure 1A). Two S. capitis subp. capitis (clinical isolates 44 and 77) failed to form biofilms under any of the studied conditions. As controls, S. epidermidis RP62A formed biofilms under all environmental conditions studied, while S. hominis SP2 did not form biofilms under any of the conditions (Figure 1A). Other hyperosmotic conditions such as the presence of $\mathrm{NaCl}$ at $2 \%(\mathrm{w} / \mathrm{v}), \mathrm{KCl}$ or $\mathrm{MgCl}_{2}$ at $2-4 \%$ $(\mathrm{w} / \mathrm{v})$ were also able to induce biofilm formation of $S$. capitis (data not shown).

Quantitative RT-PCR showed that hyperosmotic treatment stimulated expression of icaADBC in representative clinical isolates of $S$. capitis, isolates 6,80 and 91, with the mRNA levels for the icaA, icaD, icaB, icaC genes increased by 10-60fold (Figure 1B).

\section{Structural Analysis of Biofilms Formed by S. capitis Under Hyperosmotic Conditions}

We quantitatively analyzed the composition of biofilms of isolates 6 and 19, by challenging established biofilms with component-disrupting chemicals or enzymes. Isolates 6 and 19 were selected as they represented two PFGE clusters after digestion with restriction enzyme SacII (Cui et al., 2013). These two clusters were responsible for 34 out of 55 episodes of S. capitis bloodstream infections at the Royal Women's Hospital NICU between 2000 and 2005 (Cui et al., 2013). The addition of sodium metaperiodate, not DNase I or proteinase $\mathrm{K}$, to established biofilms caused detachment of $\sim 90 \%$ of the S. capitis biomass, suggesting a major role for PIA in the integrity of mature biofilms (Figure 2A). In order to visualize the relative mass of PIA in S. capitis biofilms, mature biofilms were formed on TCPS cutouts and stained with SYTO-9 and WGA. WGA is a lectin that specifically recognizes PIA in S. epidermidis biofilms (Sanford et al., 1995). Three-dimensional reconstruction of CLSM images revealed similar data from both isolates: the mass of PIA stained with WGA (Figure 2B, red) is equivalent to the cellular mass stained with SYTO-9 (Figure 2B, green) in biofilm structures and the PIA forms a surface cap across the top of the cellular layer.

\section{Features of Biomaterial Surfaces Dictate the Formation of Biofilms by S. capitis}

In the initial screening, no biofilm was formed by any of the 17 S. capitis isolates under any of the tested environmental conditions if TCPS was replaced by polystyrene microplates without surface treatment (Not Treated, Corning). This observation provided an opportunity to address the features of biomaterial surfaces that stimulates biofilm formation by S. capitis isolates from the NICU. We tested biofilm formation of eight $S$. capitis isolates of the NRCS-A clone in nine commercial microplates from different companies (see Methods). Only the CellBIND and TCPS microplates supported S. capitis biofilm formation (Table 2). Contact angle measurements reflect hydrophobicity of biomaterial surfaces, but these measurements only weakly correlate with biofilm formation of S. capitis, as found in this study [correlation coefficient $r=-0.030$, CI $(-0.810,0.469)]$. AFM traces the topography of a surface and allows calculation of a mean surface roughness, but again only very week correlation was found between biofilm formation and surface roughness (Figure 3A) as measured by AFM (Figure 3B) [correlation coefficient $r=0.083$, CI $(-0.616,0.709)$ ]. XPS is a surface-sensitive technique used to quantify the elemental composition including oxygen, nitrogen and carbon content in the outer layer of biomaterials (Table 2). Here, Spearman's correlation tests demonstrated a moderate correlation between biofilm formation and surface $\% \mathrm{O}$ [correlation coefficient $r=0.567, \mathrm{CI}(-0.216,0.906)]$ or a strong correlation between biofilm formation and $\mathrm{O} / \mathrm{C}$ ratio [correlation coefficient $r=0.611$, CI $(-0.160,0.919)]$. No such correlations were found for other elements (nitrogen or carbon species detected by XPS). Information regarding functional groups can be obtained from interpreting high-resolution spectra; as carbon is typically 


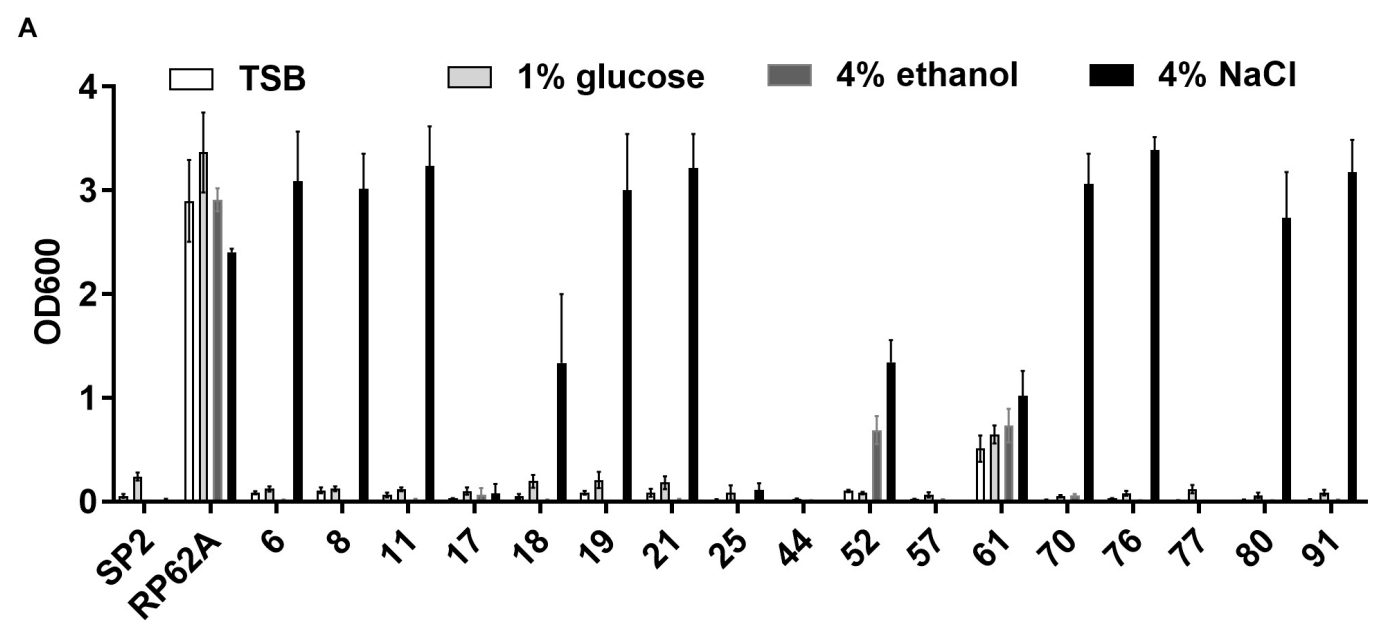

Isolates

B

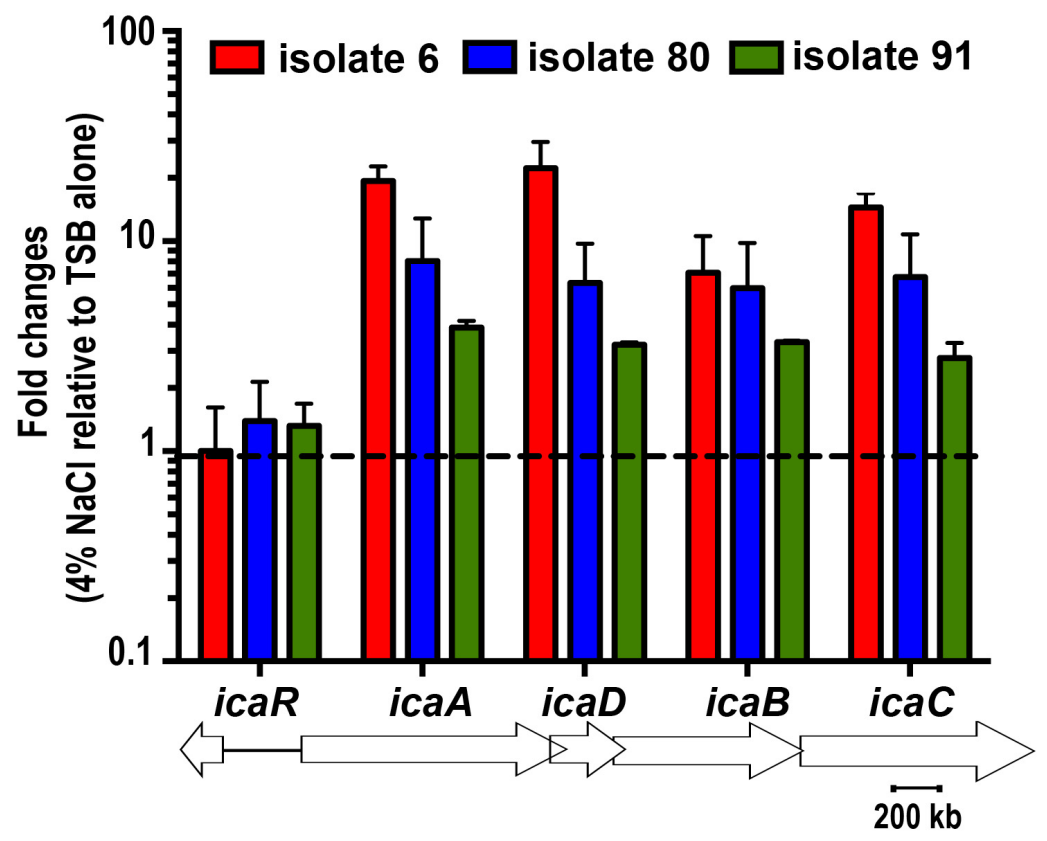

FIGURE 1 | (A) Biofilm formation of 17 clinical S. capitis isolates on tissue culture polystyrene (TCPS) surfaces under different environmental conditions. Microplates were seeded with bacteria in the indicated media, including Tryptic soya broth (TSB) only, TSB + 1\% glucose, TSB + 4\% ethanol, and TSB + 4\% NaCl. Biofilm formation was monitored using crystal violet staining. Error bars represent standard errors of the means (SEM). (B) The indicated isolates were grown in TSB or in $\mathrm{TSB}+4 \% \mathrm{NaCl}$ for $5.5 \mathrm{~h}$ and the expression of $i c a A D B C$ and ica $R$ at these two conditions were analyzed and compared by quantitative reverse transcription polymerase chain reaction (RT-PCR). Isolates $8,11,18,19$, and 21 were also examined and showed similar results as isolates 6 . Error bars represent SEM.

the most abundant element that can be detected by XPS in a polymer, it is often the most informative high-resolution spectrum (Figure 3C).

\section{Highly Oxidized Surfaces Enable}

\section{S. capitis EPS Immobilization and Promote Biofilm Maturation}

When biofilm formation was monitored in distinct untreated polystyrene microplates two representative strains of $S$. capitis (isolates 6 and 19) completed the early adherence phase of development, but failed to network the cell clusters even after $6 \mathrm{~h}$ incubation (Figure 4A). As polysaccharide was found to be the major component of $S$. capitis biofilm EPS matrix, a hypothesis was raised: a productive interaction between $S$. capitis EPS and highly oxidized surface might facilitate the networking needed for the subsequent phases of biofilm formation by $S$. capitis. Matrix materials extracted from mature biofilms of $S$. capitis could be immobilized on TCPS surfaces after a short exposure of $3 \mathrm{~h}$, but not on untreated 


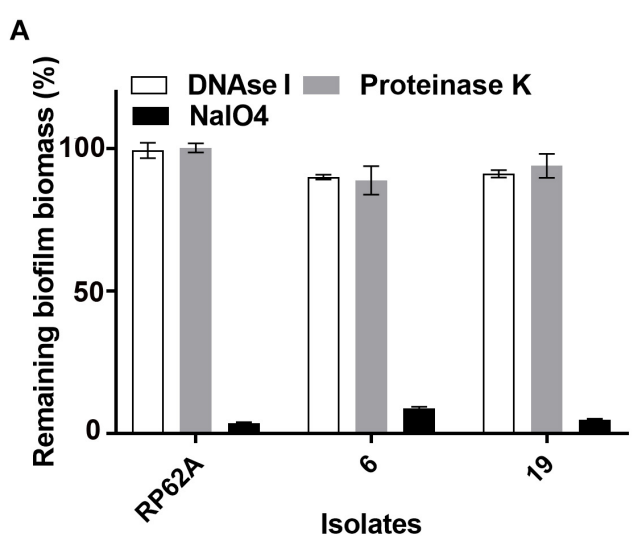

B

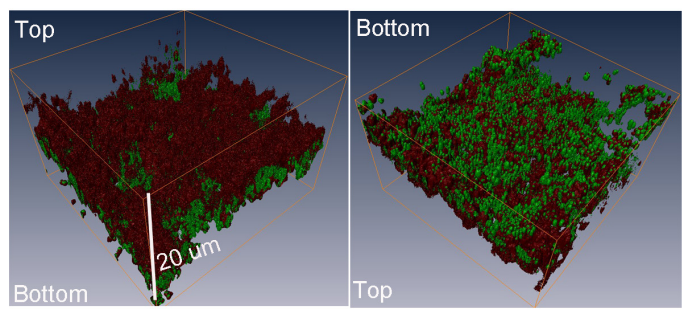

FIGURE 2 | (A) Analysis of the matrix composition of mature biofilms formed by S. capitis. (A) Mature biofilms (20 h old) were treated with 5 mg/mL of deoxyribonuclease I (DNase I), $10 \mathrm{mM}$ of sodium periodate $\left(\mathrm{NalO}_{4}\right)$, and $100 \mu \mathrm{g} / \mathrm{mL}$ of proteinase $\mathrm{K}$ for $2 \mathrm{~h}$ at $37^{\circ} \mathrm{C}$, and the remaining biomass was assessed by crystal violet staining. (B) Confocal Laser Scanning Microscopy (CLSM) of S. capitis biofilms (isolate 6). Three-dimensional reconstructions show the staining pattern for polysaccharide intercellular adhesion [PIA, wheat germ agglutinin (WGA, red)] and cell mass (SYTO-9, green). The scale bar indicates the biofilm was $\sim 20 \mu \mathrm{m}$ thick.

TABLE 2 | Biofilm formation of S. capitis on different surfaces and their elemental composition [atomic\% and atomic ratios (X/C)] derived from XPS survey spectra.

\begin{tabular}{|c|c|c|c|c|c|c|c|c|c|c|c|c|c|c|c|}
\hline \multicolumn{2}{|c|}{ 96-well microplates } & \multicolumn{9}{|c|}{ Biofilm formation of isolates* } & \multicolumn{3}{|c|}{$\%$ Composition } & \multicolumn{2}{|c|}{ Atomic ratios } \\
\hline Maker & Surface treatment & RP62A & 6 & 8 & 11 & 18 & 19 & 21 & 17 & 25 & $01 \mathrm{~s}$ & $\mathrm{~N}$ 1s & C 1s & $\mathrm{O} / \mathrm{C}$ & N/C \\
\hline \multirow[t]{6}{*}{ Corning } & DNA Bind & + & - & - & - & - & - & - & - & - & $5.7 \pm 0.3^{\star \star}$ & $0.8 \pm 0.1$ & $93.5 \pm 0.2$ & $0.061 \pm 0.003$ & $0.008 \pm 0.001$ \\
\hline & Carbo-BIND & + & - & - & - & - & - & - & - & - & $8.1 \pm 1.6$ & $4.7 \pm 1.2$ & $87.3 \pm 2.7$ & $0.093 \pm 0.002$ & $0.054 \pm 0.015$ \\
\hline & Universal-BIND & + & - & - & - & - & - & - & - & - & $6.2 \pm 0.5$ & NA & $93.8 \pm 0.5$ & $0.066 \pm 0.005$ & NA \\
\hline & Not Treated & + & - & - & - & - & - & - & - & - & $6.2 \pm 0.3$ & NA & $93.8 \pm 0.3$ & $0.066 \pm 0.004$ & NA \\
\hline & CellBIND & + & + & + & + & + & + & + & - & - & $20.9 \pm 0.5$ & $1.2 \pm 0.3$ & $77.9 \pm 0.6$ & $0.269 \pm 0.009$ & $0.015 \pm 0.004$ \\
\hline & Ultra-Low Attachment & + & - & - & - & - & - & - & - & - & $13.9 \pm 1.0$ & $11.0 \pm 0.8$ & $75.1 \pm 1.7$ & $0.185 \pm 0.018$ & $0.147 \pm 0.014$ \\
\hline \multirow[t]{2}{*}{ NUNC } & Immobilizer & + & - & - & - & - & - & - & - & - & $12.2 \pm 0.4$ & NA & $87.8 \pm 0.4$ & $0.139 \pm 0.005$ & NA \\
\hline & TCPS & + & + & + & + & + & + & + & - & - & $15.9 \pm 0.2$ & NA & $84.1 \pm 0.2$ & $0.190 \pm 0.002$ & NA \\
\hline Falcon & TCPS & + & + & + & + & + & + & + & - & - & $16.4 \pm 0.3$ & NA & $83.6 \pm 0.3$ & $0.196 \pm 0.004$ & NA \\
\hline \multicolumn{16}{|c|}{ MODIFIED SURFACES } \\
\hline \multicolumn{2}{|c|}{ Ozone treated } & + & + & + & + & + & + & + & - & - & $11.9 \pm 0.4$ & NA & $88.1 \pm 0.4$ & $0.135 \pm 0.005$ & NA \\
\hline \multicolumn{2}{|c|}{ DGpp treated } & + & + & + & + & + & + & + & - & - & $19.3 \pm 0.2$ & NA & $80.7 \pm 0.2$ & $0.239 \pm 0.003$ & NA \\
\hline
\end{tabular}

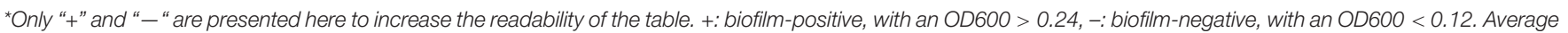

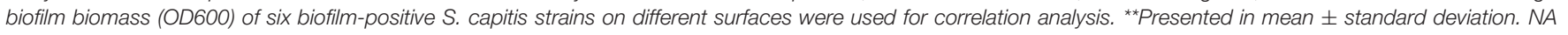
means there is no signal. XPS, X-ray photoelectron spectroscopy; O, oxygen; N, nitrogen; C, carbon; DGpp, diethylene glycol dimethyl ether plasma polymer.

polystyrene surface even when the exposure was extended to 20 h (Figure 4B).

\section{Surface Chemistry of Pediatric Central Venous Catheters and S. capitis Biofilm Formation}

To determine whether the model polystyrene surfaces are reflective of the surface of vascular access devices, sections of pediatric CVCs were subjected to biofilm formation and XPS analysis (Figure 5 and Table 3). Surfaces of untreated CVCs were found to have typical polyurethane surface chemistry (as per manufacturer's information), but additional properties also, and partially supported biofilm formation of S. capitis under hyperosmotic conditions (Table 3 and Figure 5). Both exterior and interior surfaces of the untreated CVC contain oxygen
(10.7 $\pm 0.0 \%$ and $8.6 \pm 0.2 \%$, respectively) (Table 3). Exposure of CVCs to serum increased the oxygen level of exterior and interior surfaces to $16.9 \pm 0.4 \%$ and $13.2 \pm 0.8 \%$, respectively, similar to that of biofilm-positive polystyrene surfaces, and supported more robust biofilm growth (Figure 5).

\section{DISCUSSION}

S. capitis has been only occasionally linked to several infections in adult patients, including infective endarteritis, prosthetic joint infections, catheter-related peritonitis, skin and soft-tissue infections, prosthetic valve endocarditis and meningitis (Oud, 2011; Takano et al., 2011; Basic-Jukic, 2017; Tevell et al., 2017; Lourtet-Hascoet et al., 2018; Natsis and Cohen, 2018; Yamamoto and Ohmagari, 2018). This opportunistic pathogen seems to have 


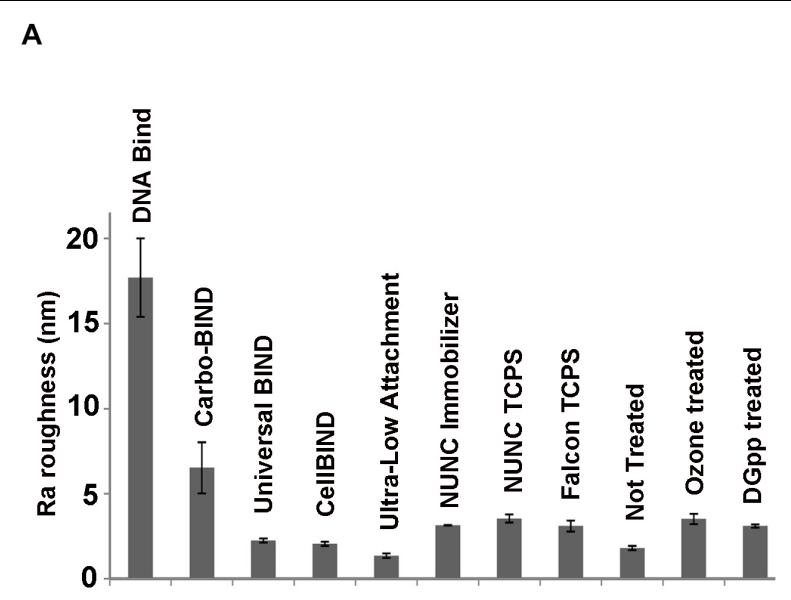

C

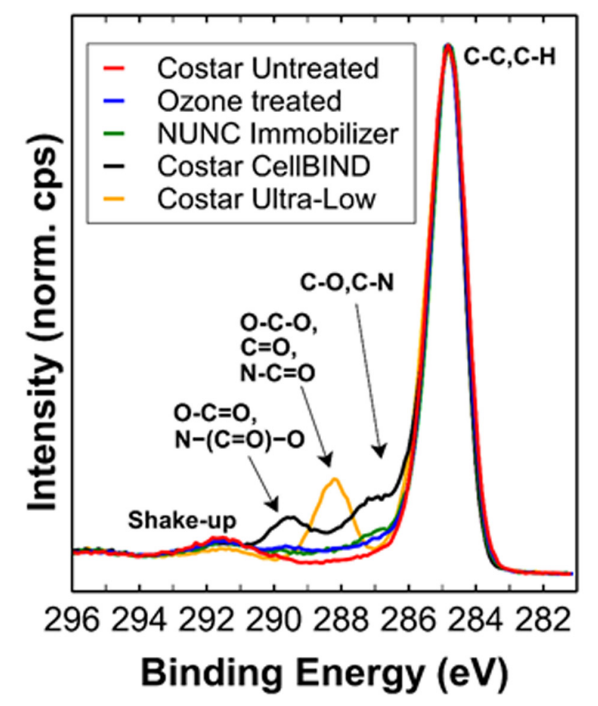

B

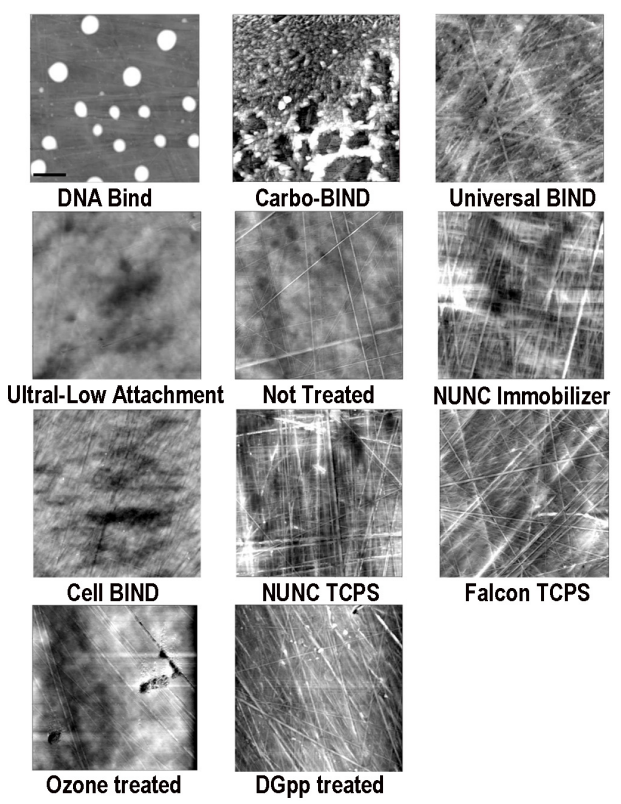

FIGURE 3 | Physicochemical characterization of biomaterial surfaces. (A) Roughness (Ra) values of different surfaces used in this study calculated from atomic force microscopy (AFM) scanning. Error bars represent SEM. (B) AFM tapping mode images of surface topographies. Images were collected over $10 \times 10 \mu m$ areas on microplates. For the DNA-Bind surface, the height trace image is displayed at $100 \mathrm{~nm}$ scale; all other images are displayed at $20 \mathrm{~nm}$ scale. (C) High-resolution $\mathrm{C} 1 \mathrm{~s}$ spectral overlay including selected polystyrene samples. Spectra are normalized to maximum peak intensity of "Corning Not Treated" sample.

a greater clinical significance in the NICU, with a unique NRCS-A clone having caused many cases of severe sepsis in hospitalized neonates worldwide (Butin et al., 2016, 2017b). The current study examined biofilm formation of $S$. capitis isolated from the NICU and identified two key determinants that can be encountered in this specific clinical setting, including hyperosmotic conditions that activate the expression of biofilm operon icaADBC in S. capitis and highly oxidized surfaces that enable $S$. capitis EPS immobilization and biofilm maturation.

Biofilm formation of $S$. capitis has been found to be distinct from that of other coagulase-negative staphylococci that also cause CRBSI in the NICU (Cui et al., 2013). Using an evolutionary model proposed by Qin et al. (2007) and data from Cui et al. (2013), we determined that biofilm formation of S. capitis isolated from the NICU was still at an early-mid stage in evolution: the majority of isolates are biofilm-positive through their ability to secrete sufficient PIA (ica+, PIA+); several isolates are able to express ica gene in response to hyperosmotic stimuli, but fail to produce PIA or form biofilms (ica+, PIA-). This is not surprising as the NICU was first introduced in 1960s and the evolutionary driving forces arising from the selection pressure of antibiotics for S. capitis are relatively contemporary. The (ica+, PIA-) phenotype has been previously characterized: isolate 17 , for example, has a small deletion that removes three hydrophobic amino acids from 

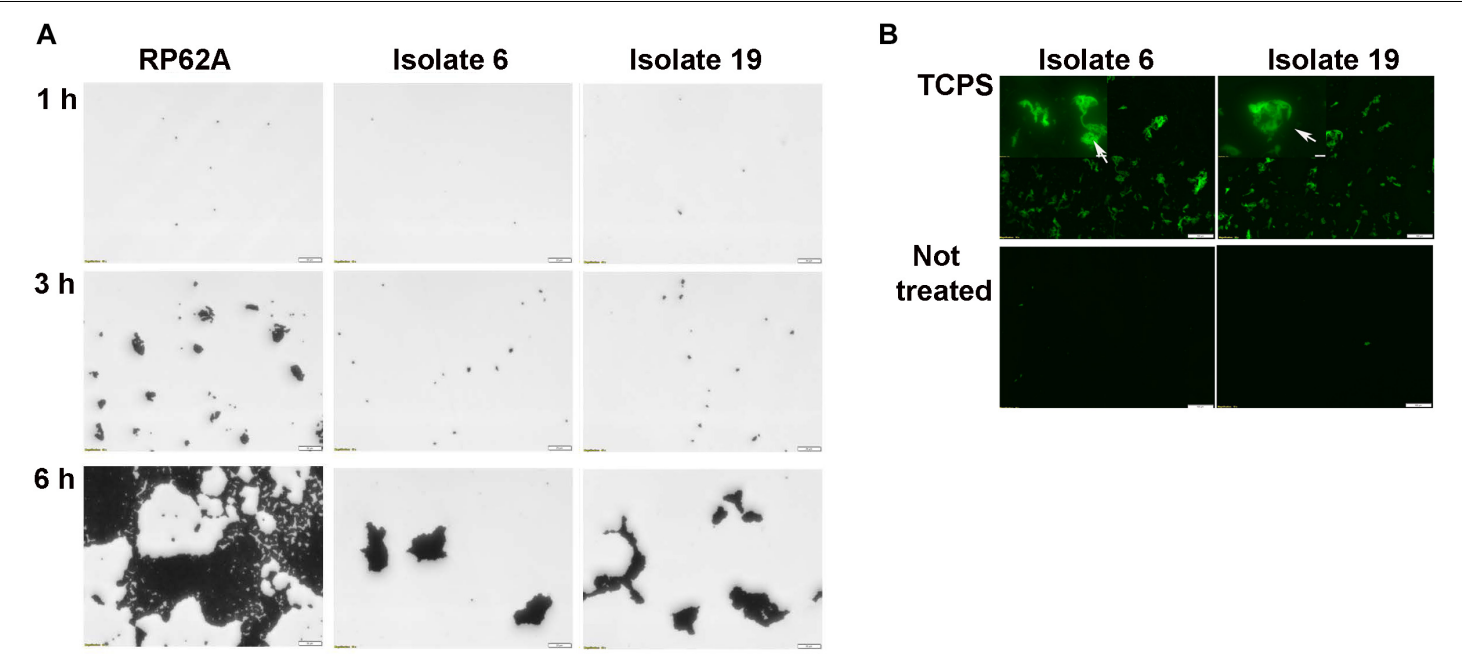

FIGURE 4 | Characterization of biofilm development of S. capitis isolates 6 and 19 on tissue culture polystyrene (TCPS) and Not Treated surfaces. (A) Biofilm development on the Not Treat surface in the first $6 \mathrm{~h}$ monitored by crystal violet staining and light microscopy. S. capitis isolates 6 and 19 failed to network their microcolony structures and form biofilms on Not Treated surfaces. S. epidermidis RP62a, used as a control, formed typical macrocolonies on the Not Treated surface at $6 \mathrm{~h}$. Scale bar $=20 \mu \mathrm{m}$. (B) Biofilm matrix of S. capitis isolates 6 and 9 was extracted, and the soluble extract was incubated with either TCPS or Not Treated surfaces, followed by wheat germ agglutinin (WGA) staining and fluorescence microscopy. Scale bar $=100 \mu \mathrm{m}$.

A

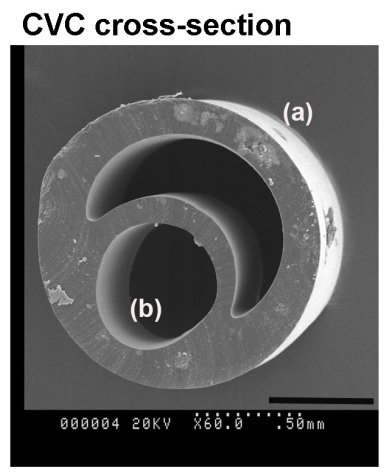

B
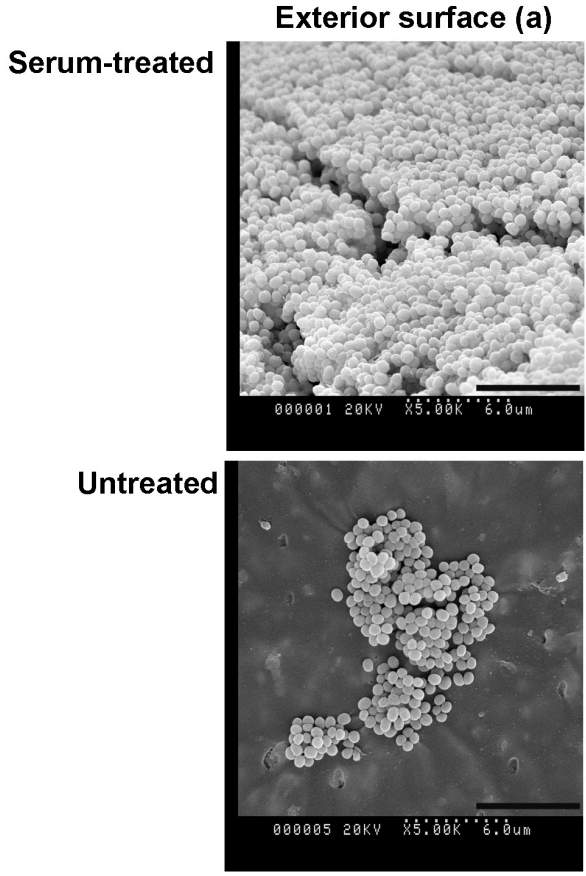
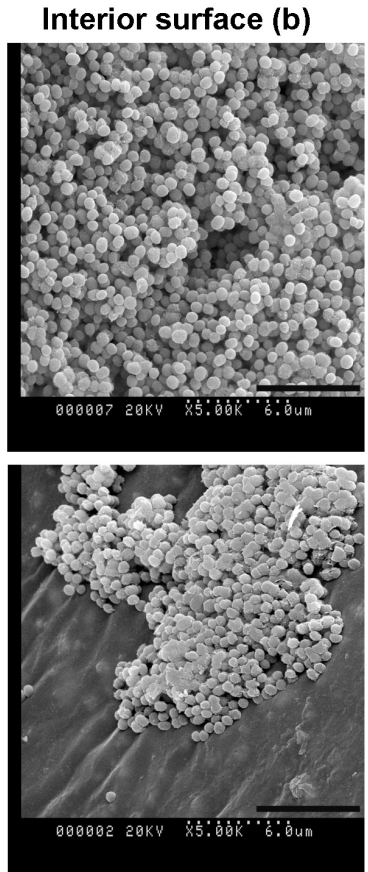

FIGURE 5 |S. capitis biofilm growth on pediatric central venous catheters (CVCs). (A) A cross-section of the double-lumen central venous catheter is shown, denoting the exterior surface (a), and interior surfaces (b). (B) CVCs were pre-treated with or without fetal bovine serum (FBS) overnight. After cultivation with S. capitis isolate 6 , catheter sections were prepared for scanning electron microscopy; representative micrographs show robust biofilms on surfaces of serum-treated CVCs that contain high percentages of oxygen element. Scale bar $=0.5 \mathrm{~mm}$ (cross sections images) or $6 \mu \mathrm{m}$ (other images).

one of the critical transmembrane segments in IcaA, which would prevent IcaA assembly in the membrane and thereby prevent PIA production and biofilm formation (Cui et al., 2013). It is also possible that other ica-independent molecular mechanisms might have been involved. Carter et al. (2018) recently reported that in contrast to the majority of NICU-associated $S$. capitis isolates that harbor embp, 2 out of 29 neonatal S. capitis clinical isolates lack this gene. Embp encodes a multifunctional cell 
TABLE 3 | Elemental composition [atomic\% and atomic ratios (X/C)] of pediatric CVCs derived from XPS survey spectra.

\begin{tabular}{|c|c|c|c|c|c|c|c|c|c|c|}
\hline \multirow[t]{2}{*}{ CVCs } & \multirow[t]{2}{*}{ Surfaces } & \multicolumn{7}{|c|}{$\%$ composition } & \multicolumn{2}{|c|}{ Atomic ratios } \\
\hline & & Si $2 p$ & S 2p & C $1 \mathrm{~s}$ & N 1s & $01 \mathrm{~s}$ & $\mathrm{Ba} 3 \mathrm{~d}$ & $\mathrm{Na} 1 \mathrm{~s}$ & O/C & N/C \\
\hline \multirow[t]{2}{*}{ Untreated } & Exterior & $5.2 \pm 0.0^{\star}$ & NA & $80.7 \pm 0.2$ & $3.5 \pm 0.2$ & $10.7 \pm 0.0$ & NA & NA & $0.132 \pm 0.000$ & $0.043 \pm 0.003$ \\
\hline & Interior & $1.3 \pm 0.1$ & $0.2 \pm 0.0$ & $85.8 \pm 0.3$ & $4.0 \pm 0.1$ & $8.6 \pm 0.2$ & $0.2 \pm 0.0$ & NA & $0.100 \pm 0.002$ & $0.046 \pm 0.001$ \\
\hline \multirow[t]{2}{*}{ Serum-treated } & Exterior & $9.4 \pm 1.1^{\star}$ & NA & $69.7 \pm 1.1$ & $3.8 \pm 0.5$ & $16.9 \pm 0.4$ & NA & $0.1 \pm 0.0$ & $0.243 \pm 0.010$ & $0.055 \pm 0.006$ \\
\hline & Interior & $2.1 \pm 0.0$ & NA & $77.4 \pm 1.4$ & $6.9 \pm 0.7$ & $13.2 \pm 0.8$ & NA & $0.4 \pm 0.0$ & $0.170 \pm 0.013$ & $0.089 \pm 0.010$ \\
\hline
\end{tabular}

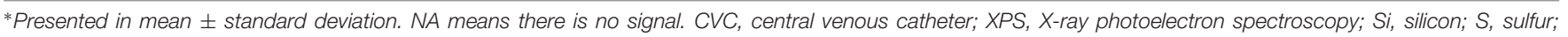
C, carbon, N, nitrogen; O, oxygen; Ba, Barium; Na, sodium.

surface fibronectin binding protein and is critical for biofilm formation of $S$. capitis (Carter et al., 2018).

Unlike its close relative $S$. epidermidis that forms biofilms under many environmental conditions, S. capitis from the NICU appears to produce biofilms only under specific conditions. Most $S$. capitis isolates from the NICU require hyperosmotic condition for the activation of $i c a A D B C$ and biofilm formation. Total parental nutrient (TPN) is frequently used in the NICU and might be the major source of hyperosmolarity. TPN has an osmolality up to $900 \mathrm{mOsm} / \mathrm{L}, \sim 3$ times that of physiological saline (Boullata et al., 2014). Previous studies have listed infusion of TPN as an independent risk factor for biofilm-related CRBSI in the NICU (Beck-Sague et al., 1994; Boullata et al., 2014). Other infusates that might confer hyperosmolarity in the NICU include $3 \% \mathrm{NaCl}$ solution that are occasionally used for the management of hyponatremia. Our study has also found that an osmolarity as low as twice that of physiological saline readily induced biofilm formation of $S$. capitis. Preventing $S$. capitis infections by manipulating the osmolarity of infusates in the NICU is thus less feasible.

A more practical strategy to prevent CRBSI in the NICU is to use non-permissive biomaterials for CVCs. We focused on the interaction between $S$. capitis and biomaterial surfaces. Although silicone and polyurethane are often preferred biomaterials for implantable medical devices including CVCs, we used polystyrene microplates to establish screening conditions to understand the formation of biofilms by $S$. capitis. The uniform sized and flat surfaces of these polystyrene microplates provided an ideal platform for quantitative and physicochemical analysis of biofilm formation. The available knowledge of how these commercially available surfaces are fabricated from the manufactures allows us to comparatively analyze surfaces that have different biological responses.

Analysis of the surface hydrophobicity and topography did not reveal differences in the surfaces examined that would explain the success or failure of biofilm formation. These findings are consistent with studies by others that found no significant correlation between biofilm formation of $S$. epidermidis and $S$. aureus and the contact angle, free energy, or roughness of biomaterial surfaces (Tidwell et al., 1997; Gottenbos et al., 2001; Hook et al., 2012). Surface chemistry however seems to play a critical role in the biofilm formation of Staphylococcus spp. (Hook et al., 2012; Mikulskis et al., 2018). We show that oxygen species present in the surface layer are essential for biofilm formation of $S$. capitis: deliberate derivatization with oxygen species was necessary and sufficient to convert a surface that was non-permissive for biofilm formation into one which supported biofilm growth.

It has been proposed that surface cell growth correlates better to specific oxygen-containing functionalities than total oxygen content of a substratum (Tidwell et al., 1997; Hook et al., 2012). With the knowledge of how these surfaces are fabricated, and comparing $\mathrm{O} / \mathrm{C}$ values presented in Table 2 and the high-resolution $\mathrm{C}$ 1s spectra (Figure 3C), it is expected that biofilm formation is also dependent on how the oxygen is presented at the surface, i.e., the functional groups. For example, surfaces of NUNC Immobilizer $(O / C=0.14)$ and Ozone treated $(O / C=0.14)$ microplates have almost identical concentrations of $\mathrm{O}$, but biofilm formation occurs only in the Ozone treated microplate. A significant difference between these two microplates is the local environment of the $\mathrm{O}$ species on the surface which is influenced by how the oxygen was introduced to the surface. Ozone treatment of polystyrene surfaces is a non-specific modification that introduces a range of $\mathrm{O}$ species such as $\mathrm{C}-\mathrm{O}, \mathrm{C}=\mathrm{O}, \mathrm{O}-\mathrm{C}-\mathrm{O}$, and $\mathrm{O}-\mathrm{C}=\mathrm{O}$. This observation applies to all the surfaces that tested positive for biofilm formation in this study, as alternative discharge-based strategies employed herein such as Corona-gas treatment used for the CellBIND surface (as per manufacture's specification) are non-specific. In contrast, biofilm-negative NUNC Immobilizer is described by the manufacturer as presenting an ethylene glycol spacer and a stable electrophilic group, i.e., the surface chemistry is well-defined. The surface of Corning Ultra-Low Attachment microplate, which presents one of the highest values for $\mathrm{O} / \mathrm{C}(0.19)$ is another well-defined biofilm-negative surface, described as having a covalently bound hydrogel layer (as per manufacture's specification), with the elemental quantification and $\mathrm{C}$ 1s spectrum suggesting a significant amount of amide groups present on the surface. All these suggest that surface treatments that introduce sufficient oxygen species in a nonspecific manner result in biofilm formation. Findings derived from model polystyrene surfaces are further supported by experimental results from pediatric CVCs. Exposure of CVCs to serum significantly increased the oxygen composition of the surfaces, possibly due to the deposition of a conditioning film of host serum components, including proteins and electrolytes on the CVC surfaces. Such a conditioning film facilitates biofilm formation of $S$. capitis. 
To address the detailed role of surface oxygen species in the biofilm formation of $S$. capitis, we further assessed the interaction between $S$. capitis biofilm EPS and biomaterial surfaces. It is wellknown that EPS matrix plays an important role in the stability and antimicrobial resistance of mature biofilms (Flemming and Wingender, 2010). By biochemically dissecting the composition of $S$. capitis biofilms, we found PIA to be the predominant component of EPS matrix. This was further confirmed by high-resolution imaging using CLSM and PIA-specific staining. A specific binding between oxygen species and PIA was found: only on highly oxidized surfaces does PIA function as a crucial surface-binding adhesin, networking microcolonies and enabling the maturation stages of biofilm formation; otherwise similar surfaces were non-permissive to biofilm development.

Given the importance of biofilm formation in hospitalacquired infections, a deep understanding of the role that surface chemistry plays in this microbial developmental process offers opportunities for novel interventions. Based on our findings, we conclude that reducing the level of oxygen species on the biomaterial surface, for examples, using low-fouling surfaces for CVCs against protein adsorption (Salwiczek et al., 2014), as well as avoiding hyperosmotic treatments wherever possible would be a strategy to minimize infusion- and catheter-related S. capitis infections in the NICU. An evident limitation of this study is that it still suffers from an inability to comprehensively reflect the complexity of in vivo conditions in the NICU. Future studies that closely mimic the NICU environment and use CVCs with different surface oxygen levels should be conducted to verify the in vitro findings from this study.

\section{REFERENCES}

Arciola, C. R., Baldassarri, L., and Montanaro, L. (2001). Presence of icaA and $i c a D$ genes and slime production in a collection of staphylococcal strains from catheter-associated infections. J. Clin. Microbiol. 39, 2151-2156. doi: 10.1128/ JCM.39.6.2151-2156.2001

Basic-Jukic, N. (2017). Acute peritonitis caused by Staphylococcus capitis in a peritoneal dialysis patient. Perit. Dial. Int. 37, 115-116. doi: 10.3747/pdi.2016. 00083

Beck-Sague, C. M., Azimi, P., Fonseca, S. N., Baltimore, R. S., Powell, D. A., Bland, L. A., et al. (1994). Bloodstream infections in neonatal intensive care unit patients: results of a multicenter study. Pediatr. Infect. Dis. J. 13, 1110-1116.

Ben Said, M., Hays, S., Bonfils, M., Jourdes, E., Rasigade, J. P., Laurent, F., et al. (2016). Late-onset sepsis due to Staphylococcus capitis 'neonatalis' in lowbirthweight infants: a new entity? J. Hosp. Infect. 94, 95-98. doi: 10.1016/j.jhin. 2016.06.008

Blanchard, A. C., Fortin, E., Rocher, I., Moore, D. L., Frenette, C., Tremblay, C., et al. (2013). Central line-associated bloodstream infection in neonatal intensive care units. Infect. Control Hosp. Epidemiol. 34, 1167-1173. doi: 10.1086/ 673464

Boullata, J. I., Gilbert, K., Sacks, G., Labossiere, R. J., Crill, C., Goday, P., et al. (2014). A.S.P.E.N. clinical guidelines: parenteral nutrition ordering, order review, compounding, labeling, and dispensing. JPEN J. Parenter Enteral. Nutr. 38, 334-377. doi: 10.1177/0148607114521833

Bradford, R., Abdul Manan, R., Daley, A. J., Pearce, C., Ramalingam, A., D’mello, D., et al. (2006). Coagulase-negative staphylococci in very-low-birth-weight infants: inability of genetic markers to distinguish invasive strains from blood culture contaminants. Eur. J. Clin. Microbiol. Infect. Dis. 25, 283-290. doi: 10.1007/s10096-006-0130-2

Butin, M., Claris, O., and Laurent, F. (2019). Clinical impact of vancomycin heteroresistance in staphylococcal strains involved in neonatal sepsis:

\section{DATA AVAILABILITY STATEMENT}

The datasets generated for this study are available on request to the corresponding author.

\section{AUTHOR CONTRIBUTIONS}

YQ, TL, YL, and AP conceived and designed the experiments. YQ, YL, DC, and CE performed the experiments. YQ, TL, XZ, MZ, YL, DC, CE, HT, MS, HT, AD, JF, and BM analyzed the data. TL, HT, AD, JF, BM, AP, and YQ contributed reagents, materials, and analysis tools. YQ, TL, YL, and CE wrote the manuscript.

\section{FUNDING}

This work was supported by the National Natural Science Foundation of China (Grant No. 81772241 to YQ) and Micro@Monash seeding Grant to YQ and YL. TL was an ARC Australian Laureate Fellow.

\section{ACKNOWLEDGMENTS}

We thank Dr. Albert Parker from the Department of Mathematical Sciences of Montana State University for advices in statistical analysis and Mrs. Joan Clark from Monash Micro Imaging for her assistance in scanning electron microscopy.

Discussion of a case report. Arch. Pediatr. 26, 236-237. doi: 10.1016/j.arcped. 2019.03.002

Butin, M., Martins-Simoes, P., Picaud, J. C., Kearns, A., Claris, O., Vandenesch, F., et al. (2015). Adaptation to vancomycin pressure of multiresistant Staphylococcus capitis NRCS-A involved in neonatal sepsis. J. Antimicrob. Chemother. 70, 3027-3031. doi: 10.1093/jac/dkv217

Butin, M., Martins-Simoes, P., Pichon, B., Leyssene, D., Bordes-Couecou, S., Meugnier, H., et al. (2017a). Emergence and dissemination of a linezolidresistant Staphylococcus capitis clone in Europe. J. Antimicrob. Chemother. 72, 1014-1020. doi: 10.1093/jac/dkw516

Butin, M., Martins-Simoes, P., Rasigade, J. P., Picaud, J. C., and Laurent, F. (2017b). Worldwide endemicity of a multidrug-resistant Staphylococcus capitis clone involved in neonatal sepsis. Emerg. Infect. Dis. 23, 538-539. doi: 10.3201/ eid2303.160833

Butin, M., Rasigade, J. P., Martins-Simões, P., Meugnier, H., Lemriss, H., Goering, R. V., et al. (2016). Wide geographical dissemination of the multiresistant Staphylococcus capitis NRCS-A clone in neonatal intensive-care units. Clin. Microbiol. Infect. 22, 46-52. doi: 10.1016/j.cmi.2015.09.008

Carter, G. P., Ussher, J. E., Da Silva, A. G., Baines, S. L., Heffernan, H., Riley, T. V., et al. (2018). Genomic analysis of multiresistant Staphylococcus capitis associated with neonatal sepsis. Antimicrob. Agents Chemother. 62, e898-e818. doi: 10.1128/AAC.00898-18

Chaffin, D. O., Taylor, D., Skerrett, S. J., and Rubens, C. E. (2012). Changes in the Staphylococcus aureus transcriptome during early adaptation to the lung. PLoS One 7:e41329. doi: 10.1371/journal.pone.0041329

Cheong, S. M., Totsu, S., Nakanishi, H., Uchiyama, A., and Kusuda, S. (2016). Outcomes of peripherally inserted double lumen central catheter in very low birth weight infants. J. Neonatal. Perinatal. Med. 9, 99-105. doi: 10.3233/NPM16915054

Cui, B., Smooker, P. M., Rouch, D. A., Daley, A. J., and Deighton, M. A. (2013). Differences between two clinical Staphylococcus capitis subspecies as revealed 
by biofilm, antibiotic resistance, and pulsed-field gel electrophoresis profiling. J. Clin. Microbiol. 51, 9-14. doi: 10.1128/JCM.05124-11

De Silva, G. D. I., Kantzanou, M., Justice, A., Massey, R. C., Wilkinson, A. R., Day, N. P. J., et al. (2002). The ica operon and biofilm production in coagulasenegative staphylococci associated with carriage and disease in a neonatal intensive care unit. J. Clin. Microbiol. 40, 382-388. doi: 10.1128/jcm.40.02.382388.2002

Deighton, M. A., Capstick, J., Domalewski, E., and Van Nguyen, T. (2001). Methods for studying biofilms produced by Staphylococcus epidermidis. Methods Enzymol. 336, 177-195. doi: 10.1016/s0076-6879(01) 36589-8

D’mello, D., Daley, A. J., Rahman, M. S., Qu, Y., Garland, S., Pearce, C., et al. (2008). Vancomycin heteroresistance in bloodstream isolates of Staphylococcus capitis. J. Clin. Microbiol. 46, 3124-3126. doi: 10.1128/JCM.00592-08

Dubbink-Verheij, G. H., Bekker, V., Pelsma, I. C. M., Van Zwet, E. W., SmitsWintjens, V., Steggerda, S. J., et al. (2017). Bloodstream infection incidence of different central venous catheters in neonates: A descriptive cohort study. Front. Pediatr. 5:142. doi: 10.3389/fped.2017.00142

Flemming, H. C., and Wingender, J. (2010). The biofilm matrix. Nat. Rev. Microbiol. $8,623-633$.

Frebourg, N. B., Lefebvre, S., Baert, S., and Lemeland, J. F. (2000). PCR-Based assay for discrimination between invasive and contaminating Staphylococcus epidermidis strains. J. Clin. Microbiol. 38, 877-880.

Galdbart, J. O., Allignet, J., Tung, H. S., Ryden, C., and El Solh, N. (2000). Screening for Staphylococcus epidermidis markers discriminating between skinflora strains and those responsible for infections of joint prostheses. J. Infect. Dis. 182, 351-355. doi: 10.1086/315660

Gerke, C., Kraft, A., Sussmuth, R., Schweitzer, O., and Gotz, F. (1998). Characterization of the $\mathrm{N}$-acetylglucosaminyltransferase activity involved in the biosynthesis of the Staphylococcus epidermidis polysaccharide intercellular adhesin. J. Biol. Chem. 273, 18586-18593. doi: 10.1074/jbc.273.29. 18586

Gilbert, R., Brown, M., Rainford, N., Donohue, C., Fraser, C., Sinha, A., et al. (2019). Antimicrobial-impregnated central venous catheters for prevention of neonatal bloodstream infection (PREVAIL): an open-label, parallel-group, pragmatic, randomised controlled trial. Lancet Child Adolesc. Health 3, 381-390. doi: 10.1016/S2352-4642(19)30114-2

Gottenbos, B., Grijpma, D. W., Van Der Mei, H. C., Feijen, J., and Busscher, H. J. (2001). Antimicrobial effects of positively charged surfaces on adhering Gram-positive and Gram-negative bacteria. J. Antimicrob. Chemother. 48, 7-13. doi: $10.1093 / \mathrm{jac} / 48.1 .7$

Heilmann, C., Schweitzer, O., Gerke, C., Vanittanakom, N., Mack, D., and Gotz, F. (1996). Molecular basis of intercellular adhesion in the biofilm-forming Staphylococcus epidermidis. Mol. Microbiol. 20, 1083-1091. doi: 10.1111/j.13652958.1996.tb02548.x

Hitzenbichler, F., Simon, M., Salzberger, B., and Hanses, F. (2017). Clinical significance of coagulase-negative staphylococci other than S. epidermidis blood stream isolates at a tertiary care hospital. Infection 45, 179-186. doi: 10.1007/ s15010-016-0945-4

Hook, A. L., Chang, C. Y., Yang, J., Luckett, J., Cockayne, A., Atkinson, S., et al. (2012). Combinatorial discovery of polymers resistant to bacterial attachment. Nat. Biotechnol. 30, 868-875. doi: 10.1038/nbt.2316

Li, Y., Muir, B. W., Easton, C. D., Thomsen, L., Nisbet, D. R., and Forsythe, J. S. (2014). A study of the initial film growth of PEG-like plasma polymer films via XPS and NEXAFS. Appl. Surf. Sci. 288, 288-294.

Lourtet-Hascoet, J., Felice, M. P., Bicart-See, A., Bouige, A., Giordano, G., and Bonnet, E. (2018). Species and antimicrobial susceptibility testing of coagulasenegative staphylococci in periprosthetic joint infections. Epidemiol Infect. 146, 1771-1776. doi: 10.1017/S0950268818001437

Mack, D., Nedelmann, M., Krokotsch, A., Schwarzkopf, A., Heesemann, J., and Laufs, R. (1994). Characterization of transposon mutants of biofilm-producing Staphylococcus epidermidis impaired in the accumulative phase of biofilm production: genetic identification of a hexosamine-containing polysaccharide intercellular adhesin. Infect. Immun. 62, 3244-3253.

Mikulskis, P., Hook, A., Dundas, A. A., Irvine, D., Sanni, O., Anderson, D., et al. (2018). Prediction of broad-spectrum pathogen attachment to coating materials for biomedical devices. ACS Appl. Mater. Interfaces 10, 139-149. doi: 10.1021/ acsami.7b14197
Natsis, N. E., and Cohen, P. R. (2018). Coagulase-negative staphylococcus skin and soft tissue infections. Am. J. Clin. Dermatol. 19, 671-677. doi: 10.1007/s40257018-0362-9

Ory, J., Cazaban, M., Richaud-Morel, B., Di Maio, M., Dunyach-Remy, C., Pantel, A., et al. (2019). Successful implementation of infection control measure in a neonatal intensive care unit to combat the spread of pathogenic multidrug resistant Staphylococcus capitis. Antimicrob. Resist. Infect. Control. 8:57. doi: 10.1186/s13756-019-0512-8

Otto, M. (2008). Staphylococcal biofilms. Curr. Top. Microbiol. Immunol. 322, 207-228.

Otto, M. (2013). Staphylococcal infections: mechanisms of biofilm maturation and detachment as critical determinants of pathogenicity. Annu. Rev. Med. 64, 175-188. doi: 10.1146/annurev-med-042711-140023

Oud, L. (2011). Community-acquired meningitis due to Staphylococcus capitis in the absence of neurologic trauma, surgery, or implants. Heart Lung. 40, 467-471. doi: 10.1016/j.hrtlng.2010.09.002

Payne, N. R., Carpenter, J. H., Badger, G. J., Horbar, J. D., and Rogowski, J. (2004). Marginal increase in cost and excess length of stay associated with nosocomial bloodstream infections in surviving very low birth weight infants. Pediatrics 114, 348-355. doi: 10.1542/peds.114.2.348

Qin, Z., Yang, X., Yang, L., Jiang, J., Ou, Y., Molin, S., et al. (2007). Formation and properties of in vitro biofilms of ica-negative Staphylococcus epidermidis clinical isolates. J. Med. Microbiol. 56, 83-93. doi: 10.1099/jmm.0.46799-0

Qu, Y., Istivan, T. S., Daley, A. J., Rouch, D. A., and Deighton, M. A. (2009). Comparison of various antimicrobial agents as catheter lock solutions: preference for ethanol in eradication of coagulase-negative staphylococcal biofilms. J. Med. Microbiol. 58, 442-450. doi: 10.1099/jmm.0. 006387-0

Rasigade, J. P., Raulin, O., Picaud, J. C., Tellini, C., Bes, M., Grando, J., et al. (2012). Methicillin-resistant Staphylococcus capitis with reduced vancomycin susceptibility causes late-onset sepsis in intensive care neonates. PLoS One 7:e31548. doi: 10.1371/journal.pone.0031548

Salwiczek, M., Qu, Y., Gardiner, J., Strugnell, R. A., Lithgow, T., Mclean, K. M., et al. (2014). Emerging rules for effective antimicrobial coatings. Trends Biotechnol. 32, 82-90. doi: 10.1016/j.tibtech.2013.09.008

Sanford, B. A., Thomas, V. L., Mattingly, S. J., Ramsay, M. A., and Miller, M. M. (1995). Lectin-biotin assay for slime present in in situ biofilm produced by Staphylococcus epidermidis using transmission electron microscopy (TEM). J. Ind. Microbiol. 15, 156-161. doi: 10.1007/bf01569820

Schmittgen, T. D., and Livak, K. J. (2008). Analyzing real-time PCR data by the comparative C(T) method. Nat. Protoc. 3, 1101-1108. doi: 10.1038/nprot. 2008.73

Stenmark, B., Hellmark, B., and Soderquist, B. (2019). Genomic analysis of Staphylococcus capitis isolated from blood cultures in neonates at a neonatal intensive care unit in Sweden. Eur. J. Clin. Microbiol. Infect. Dis. 38, 2069-2075. doi: 10.1007/s10096-019-03647-3

Taff, H. T., Nett, J. E., Zarnowski, R., Ross, K. M., Sanchez, H., Cain, M. T., et al. (2012). A Candida biofilm-induced pathway for matrix glucan delivery: implications for drug resistance. PLoS Pathog. 8:e1002848. doi: 10.1371/journal. ppat. 1002848

Takano, T., Ohtsu, Y., Terasaki, T., Wada, Y., and Amano, J. (2011). Prosthetic valve endocarditis caused by Staphylococcus capitis: report of 4 cases. J. Cardiothorac. Surg. 6:131. doi: 10.1186/1749-8090-6-131

Telford, A. M., Meagher, L., Glattauer, V., Gengenbach, T. R., Easton, C. D., and Neto, C. (2012). Micropatterning of polymer brushes: grafting from dewetting polymer films for biological applications. Biomacromolecules 13, 2989-2996. doi: $10.1021 / \mathrm{bm} 3010534$

Tevell, S., Hellmark, B., Nilsdotter-Augustinsson, A., and Soderquist, B. (2017). Staphylococcus capitis isolated from prosthetic joint infections. Eur. J. Clin. Microbiol. Infect. Dis. 36, 115-122.

Tidwell, C. D., Ertel, S. I., Ratner, B. D., Tarasevich, B. J., Atre, S., and Allara, D. L. (1997). Endothelial cell growth and protein adsorption on terminally functionalized, self-assembled monolayers of alkanethiolates on gold. Langmuir 13, 3404-3413.

Uwamahoro, N., Qu, Y., Jelicic, B., Lo, T. L., Beaurepaire, C., Bantun, F., et al. (2012). The functions of Mediator in Candida albicans support a role in shaping species-specific gene expression. PLoS Genet. 8:e1002613. doi: 10.1371/journal. pgen. 1002613 
Vermont, C. L., Hartwig, N. G., Fleer, A., De Man, P., Verbrugh, H., Van Den Anker, J., et al. (1998). Persistence of clones of coagulase-negative staphylococci among premature neonates in neonatal intensive care units: two-center study of bacterial genotyping and patient risk factors. J. Clin. Microbiol. 36, 2485-2490.

Wang, S. M., Liu, C. C., Tseng, H. W., Yang, Y. J., Lin, C. H., Huang, A. H., et al. (1999). Staphylococcus capitis bacteremia of very low birth weight premature infants at neonatal intensive care units: clinical significance and antimicrobial susceptibility. J. Microbiol. Immunol. Infect. 32, 26-32.

Wolf, J., Connell, T. G., Allison, K. J., Tang, L., Richardson, J., Branum, K., et al. (2018). Treatment and secondary prophylaxis with ethanol lock therapy for central line-associated bloodstream infection in paediatric cancer: a randomised, double-blind, controlled trial. Lancet Infect. Dis. 18, 854-863. doi: 10.1016/S1473-3099(18)30224-X

Yamamoto, K., and Ohmagari, N. (2018). Infective endarteritis due to Staphylococcus capitis. Intern. Med. 57:1185. doi: 10.2169/internalmedicine. 0070-17

Yumani, D. F., Van Den Dungen, F. A., and Van Weissenbruch, M. M. (2013). Incidence and risk factors for catheter-associated bloodstream infections in neonatal intensive care. Acta Paediatr. 102, e293-e298. doi: 10.1111/apa. 12256

Zhou, W., Niu, D., Cao, X., Ning, M., Zhang, Z., Shen, H., et al. (2015). Clonal dissemination of linezolid-resistant Staphylococcus capitis with G2603T mutation in domain $\mathrm{V}$ of the $23 \mathrm{~S}$ rRNA and the $c f r$ gene at a tertiary care hospital in China. BMC Infect. Dis. 15:97. doi: 10.1186/s12879-015-0841-z

Conflict of Interest: The authors declare that the research was conducted in the absence of any commercial or financial relationships that could be construed as a potential conflict of interest.

Copyright (c) 2020 Qu, Li, Cameron, Easton, Zhu, Zhu, Salwiczek, Muir, Thissen, Daley, Forsythe, Peleg and Lithgow. This is an open-access article distributed under the terms of the Creative Commons Attribution License (CC BY). The use, distribution or reproduction in other forums is permitted, provided the original author(s) and the copyright owner(s) are credited and that the original publication in this journal is cited, in accordance with accepted academic practice. No use, distribution or reproduction is permitted which does not comply with these terms. 